\title{
Russian Identity in the Digital Age and social Perceptions of social media users
}

\author{
N. P. Saschenko ${ }^{1}$
}

${ }^{1}$ Center for Social Security and Risk Management, Institute of Socio-Political Research, Federal Research Institute of the Russian Academy of Sciences, 6, k. 1, Fotieva str., Moscow 119333, Russian Federation

DOI: $10.18255 / 2412-6519-2021-1-40-51$

Research Article

Full text in Russian

The article proposes approaches to solving the problem of the ongoing crisis of nationalstate identification of young citizens of Russia and the associated socio-political risks of a delayed nature. Digitalization radically changes the structure of employment of the population, the nature of socio-economic and socio-political relations, the functioning and reproduction of the culture underlying group, ethnic, national-state identity, creates the possibility of effective cross-border external influence. These changes contain significant risks of destabilizing the state and its main institutions, the formation of a controlled "digital society". The results of the first stage of an empirical study of social representations of Russia by young users of social networks are presented. The article substantiates the dependence of national-state identity on social ideas about one's country, which are being transformed in the context of digitalization of all spheres of life. The structural-functional and contentmorphological characteristics of the social ideas of young people about Russia have been determined. Differences in the social perceptions of young people of different categories were revealed, and differences in the significance and valence of the elements of the "core" zone were revealed. It is planned to conduct the second stage of research on the structure and content of social perceptions of Russia by young users of social networks with different ideological preferences, socio-political sentiments, in order to test the significance of the elements of the "core" zone depending on political orientations.

Keywords: national-state identity; digitalization; social representations; Russia; youth; prototypical analysis; associative experiment; socio-political risks

INFORMATION ABOUT THE AUTHORS

\begin{tabular}{l|l} 
Saschenko, Natalia P. & $\begin{array}{l}\text { E-mail: nsaschenko@mail.ru } \\
\text { Cand. Sc. (Psychology), associate professor, senior researcher }\end{array}$
\end{tabular}

For citation: Saschenko N. P. Russian Identity in the Digital Age and social Perceptions of social media users // Social'nye i gumanitarnye znanija. 2021. Vol. 7, No 1. P. 40-51. (in Russ.) 


\title{
Российская идентичность в цифровую эпоху и социальные представления пользователей социальных сетей
}

\author{
Н. П. Сащенко ${ }^{1}$
}

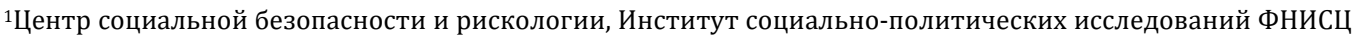
РАН, ул. Фотиевой, д. 6, к. 1, Москва, 119333, Российская Федерация

DOI: $10.18255 / 2412-6519-2021-1-40-51$

УДК 316.613 .4

Научная статья

Полный текст на русском языке

В статье предлагаются подходы к решению проблемы продолжающегося кризиса национально-государственной идентификации молодых граждан России и связанных с этим социально-политических рисков, носящих отложенный характер. Цифровизация радикальным образом меняет структуру занятости населения, характер социально-экономических и социально-политических отношений, функционирование и воспроизводство культуры, лежащей в основе групповой, этнической, национально-государственной идентичности, создает возможность эффективного трансграничного внешнего влияния. Эти изменения содержат в себе значительные риски дестабилизации государства и основных его институтов, формирования управляемого «цифрового общества». Представлены результаты первого этапа эмпирического исследования социальных представлений о России молодых пользователей социальных сетей. Обосновывается зависимость национально-государственной идентичности от социальных представлений о своей стране, трансформирующихся в условиях цифровизации всех сфер жизни. Определены структурно-функциональные и содержательно-морфологические характеристики социальных представлений молодежи о России. Выявлены различия в социальных представлениях молодежи разных категорий, а также обнаружены различия в значимости и валентности элементов зоны «ядра».

Предполагается проведение второго этапа исследования структуры и содержания социальных представлений о России молодых пользователей социальных сетей с разными идеологическим предпочтениями, социально-политическими настроениями с целью проверки значимости элементов зоны «ядра» в зависимости от политических ориентаций.

Ключевые слова: национально-государственная идентичность; цифровизация; социальные представления; Россия; молодежь; прототипический анализ; ассоциативный эксперимент; социально-политические риски

ИНФОРМАЦИЯ ОБ АВТОРАХ

Сащенко, Наталья Петровна $\mid$ E-mail: nsaschenko@mail.ru

Кандидат психологических наук, доцент, старший научный сотрудник

Для цитирования: Сащенко Н. П. Российская идентичность в цифровую эпоху и социальные представления пользователей социальных сетей // Социальные и гуманитарные знания. 2021. Том 7 , № 1. С. 40-51.

(C) Сащенко Н. П., 2021

Статья открытого доступа под лицензией СС BY (https://creativecommons.org/licenses/by/4.0/) 


\section{Введение}

Актуальность подобного исследования обусловлена растущей социальнополитической рискогенностью глобальных технологических процессов.

Цифровизация радикальным образом меняет структуру занятости населения, характер социально-экономических и социально-политических отношений, функционирование и воспроизводство культуры, лежащей в основе групповой, этнической, национально-государственной идентичности, создает возможность эффективного трансграничного внешнего влияния. Эти изменения содержат в себе значительные риски дестабилизации государства и основных его институтов, формирования управляемого «цифрового общества».

Процессы цифровизации всех сфер жизни и, как следствие, виртуализации социальных отношений и информационной среды оказывают влияние на представления граждан о реальном мире и в первую очередь молодёжи, социализация которой всё больше смещается в виртуальное пространство. Как следствие, размывается ценностно-символическое пространство национально-государственной идентичности, формируется неустойчивая и эклектичная, в отличие от реальности, картина мира, в том числе и политическая.

Пандемия же, вынужденная изоляция и масштабная, ускоренная цифровизация явились катализатором всех этих процессов, изменив режимы межличностных отношений, взаимодействия личности с семьей, ближним кругом общения, с государством и бизнесом, с глобальными субъектами. Созданы условия для совершенствования форм, инструментов, расширения границ и возможностей управления массовым сознанием через трансформацию социальных представлений. Трансформация последних возможна в силу их важнейших характеристик - умозрительности, неопределенности, отдаленности, личностной или общественной значимости [1, с.91], что создает предпосылку неустойчивости, неуверенности личности. А противоречия между самими социальными представлениями по ряду оснований (по времени, по уровню обобщенности, по значимости, по ценностному основанию) не только возможны, но и вполне способствуют возникновению и сохранению состояния неустойчивости, подтверждая функциональную роль социальных представлений как способа социального мышления личности и способа осознания ею социальной действительности.

Не все противоречащие представления становятся проблемой, многие остаются обособленными, локально существующими в ценностно-символическом пространстве. Но они чувствительны к разного рода коммуникативным стимулам сообщениям средств массовой информации, материалам из интернета, транслирующим символы агрессии, войны, протеста. Когнитивная функция социального мышления может переключить внимание пользователей (зрителей, слушателей) на других акторов политики, предлагающих другие символы и привлекательные образы в своих интересах. Все это создает риски утраты гражданской идентичности, как следствие, социально-политической устойчивости, носящие характер отложенных. 


\section{Результаты научных дискуссий}

Научные дискуссии по поводу результатов многочисленных исследований социально-политических представлений о власти, стране, обществе, политических институтах и современных процессах не только актуализируют проблемы кризисного состояния национально-государственной идентичности, но и обозначают новые грани проблемного поля и направления научного поиска.

Обеспокоенность ученых техногуманитарным дисбалансом [2], ростом разрыва между технологическим оптимизмом и социальным пессимизмом [3, c. 16 , 35; 4], появлением глобальных рисков, «режимов с обострением» [5] и в то же время уязвимостью гуманитарных технологий и систем управления в обществе риска [6], усиливающейся в условиях вынужденной социальной изоляции, требует все более пристального внимания не только к растущим сегодня технологическим возможностям, но и к последствиям влияния цифрового мира на социальное мышление, структуру и морфологию социальных представлений, отношения между людьми, на культуру в целом.

Сегодня потребность человека в идентичности выходит по значимости на одно из первых мест. Еще в начале 70-х годов XX века французский социолог Клод Леви-Строс утверждал, что кризис идентичности станет новой бедой века, и прогнозировал изменение статуса данной проблемы из социально-философского и психологического в междисциплинарный. Сегодня во многих странах мира, в том числе и в России, налицо кризис разных видов социальной идентичности, в том числе и национально-государственной идентичности $[7 ; 8 ; 9],-$ одной из наиболее важных форм самоотождествления личности. Проблема утраты идентичности переходит из социальной в политическую. Обеспокоенность ученых европейских стран возможной социально-политической нестабильностью вследствие утраты гражданами идентичности со своей страной направляет их усилия на проведение исследований зависимости формирования социальных представлений об угрозах и рисках от социально-политического и культурного контекстов [10], а также на анализ восприятия рисков и интеграции общих знаний о проблемах в целях защиты общества от потенциальных опасностей [11; $12 ; 13]$.

Особую важность приобретают исследования ученых о влиянии культуры на процесс социального мышления и обратно - влияние измененных социальных представлений на культурную матрицу, на контекстуальный смысл вопросов, связанных с риском и угрозами новой реальности [14]. Ученые отметили доминирующую роль самобытности, традиционности, базовых культурных паттернов в формировании и скорости трансформации социальных представлений общества. К примеру, в сравнении социальных представлений французских и румынских студентов о риске было обнаружено, что разница в представлениях заключалась в основном в культурных факторах [15].

Существуют позитивные примеры политической и социальной стабильности некоторых стран, несмотря на сохранение угроз, потенциально способных вызвать социальные кризисы. К примеру, сингулярность Камеруна по меньшей мере вызывает как восхищение, так и любопытство. Парадокс заключается в том, что при сохранении политических и социальных проблем, таких как неработающий процесс демократизации и устаревший политический класс [16], эндемическая 
безработица молодых выпускников [17], недостатки систем здравоохранения и образования [18] и глубокая враждебность между определенными этническими и религиозными общинами [19], стране удалось сохранить свое территориальное и политическое единство. Для некоторых ученых объяснение способности Камеруна избежать угроз нестабильности может лежать в истории страны, культурного разнообразия, социальной идентичности и социальной сплоченности [20]. А это важные слагаемые основ национально-государственной идентичности.

\section{Методологическая основа исследования}

Существенное теоретико-методологическое значение для исследования национально-государственной идентичности вообще и идентификационных образов своей страны в частности имеют теории политической социологии, политической психологии, социальной психологии. Для нас важна интерпретация российской идентичности как государственно-гражданской, включающей ответственность за дела в стране, готовность участвовать в политической жизни во имя интересов граждан страны [21;22; 23]. С участием Л. М. Дробижевой в Стратегию государственной национальной политики на период до 2025 года, подписанной Президентом в декабре 2012 г., были добавлены определения ряда понятий, в том числе общероссийской гражданской идентичности. Оно толкуется как «осознание гражданами Российской Федерации их принадлежности к своему государству, народу, обществу, ответственности за судьбу страны, необходимости соблюдения гражданских прав и обязанностей, а также приверженность базовым ценностям российского общества» ${ }^{1}$. Важен подход к исследованию российской гражданской идентичности в рамках теоретической модели политического восприятия Е. Б. Шестопал, где глубина содержания национально-государственной идентичности раскрывается через исследование психологической само-ассоциации личности с геополитическим образом определенного национально-государственного конструкта, ценностей и символических репрезентаций [24]. Также была выбрана теория социальных представлений С. Московичи [25] для определения смысловых рамок восприятия социальной реальности, формирующихся фреймов и нарративов коллективной памяти, задающих направленность изменений и устойчивость национально-государственной идентичности.

В статье анализируются результаты первого этапа эмпирического исследования социальных представлений о России, выполненного по инициативе автора в рамках Госзадания Института социально-политических исследований ФНИСЦ РАН в 2020 году.

Цель исследования заключалась в выявлении и последующем анализе структуры и содержания социальных представлений о России у молодых пользователей сетей различных половозрастных групп, с разными идеологическими предпочтениями, социально-политическими настроениями.

\footnotetext{
${ }^{1}$ Указ Президента РФ от 19 декабря 2012 г. № 1666 «О Стратегии государственной национальной политики Российской Федерации на период до 2025 года». URL: https://www.garant.ru/products/ipo/prime/doc/70184810/ (дата обращения: 29.10.2020).
} 
Были применены следующие методы исследования: онлайн-опрос пользователей социальных сетей; методика свободных ассоциаций, направленная на выявление социальных представлений по Ж.-К. Абрику [26]; контент-анализ высказываний качественно-количественной модификации; метод прототипического и категориального анализа по П. Вержесу [27].

\section{Результаты}

Первый этап эмпирического исследования структуры и содержания социальных представлений о России молодежной аудитории, пользователей социальных сетей Facebook, ВКонтакте, был завершен в июне 2020 года.

Цель исследования предполагала изучение в рамках структурного подхода Ж. К. Абрика системы образов и символов, ассоциирующихся в сознании молодежи с понятием «Россия». Опрос проходил в период изоляции в онлайн-формате через инструменты социальных сетей. Метод сбора данных - ассоциативный эксперимент. Было получено 2035 ассоциаций, выборка отремонтирована и приведена в соответствие со статистическими показателями. В логике теории «ядра и периферии» полученные по каждой из групп участников исследования ассоциации были подвергнуты прототипическому анализу по П. Вержесу. Проверялась первая гипотеза о различии социальных представлений о России в разных поло-возрастных и профессиональных группах, об устойчивости «ядра» и границ поля «периферии». В целом для сознания «цифровой» молодежи характерны противоречивость, определенная размытость и неустойчивость. Выявлены различия в социальных представлениях молодежи разных профессиональных и возрастных категорий, а также обнаружены различия в значимости и валентности элементов зоны «ядра».

В структуре полученных социальных представлений «ядро» составляют те идеи, которые отражают коллективную память молодежной группы, устойчивы и разделяются большинством группы. Центральное ядро содержит ограниченное количество элементов, которые придают смысл представлению. Эти центральные основные элементы определяются как консенсусные и неоспоримые $[28 ; 29]$. Они характеризуются «силой влияния и обеспечивают устойчивость социальных представлений, генерируя значение «ядра» и его организацию» $[30$, c. 802]. Периферийная система зависит от центрального ядра и является самой плотной, доступной и гибкой частью социальных представлений. Таким образом, периферийная система как бы защищает центральное ядро. Все это позволяет определить, как проявляются элементы центрального ядра в поведении и как зона потенциальных изменений корректирует социальное представление в целом в соответствии с контекстом.

Зона ядра социальных представлений о России по нашим результатам представлена тремя понятиями («страна», «дом», «гордость») с одинаковыми средними рангами появления в списках. Частотность выше у понятия «страна». К тому же, во всем массиве ассоциация «страна» связана с различными по смыслу ассоциациями и несет разную смысловую нагрузку. Группировка ассоциаций в понятия показала, что страна воспринимается в двух смыслах: страна как территория и страна как дом. Характеристики страны как территории попали в зону 3 и 2 - зоны 
потенциальных изменений - и они конкретизируют элементы первой зоны ядра. В эти зоны попали такие характеристики, как «огромная», «большая», «ресурсы», «потенциал», «возможности», «сила», «любовь», «держава». В зоне ядра, кроме понятия «страна», остались понятия «дом» и «гордость» как отражение теплого, трепетного отношения к своей стране, с сохранившимся чувством гордости за все достижения. Обратившись ко всему массиву, отметим, что ассоциации «Россиястрана» и «Россия-государство» представлены почти в равной мере, причём с позитивной и негативной коннотациями одновременно («страна возможностей», «богатая страна», но «государство», где преобладают «упадок», «разруха», «коррупция»). Здесь находим корреляцию наших результатов с результатами исследования, проведенного учеными факультета политологии МГУ им. М. В. Ломоносова под руководством Т. В. Евгеньевой в 2019 году, об особенности ценностно-символического пространства идентичности российской молодежи, которое характеризуется одновременно и расширением, и поляризацией содержания идентификационных образов.

Понятия «родина», «великая», «Путин», «государство» присутствуют в представлении молодежи о России и имеют высокую частоту упоминания. Но ранг их появления не позволяет говорить о том, что «родина» и «государство» являются ключевым элементом, вокруг которого формируется представление респондентов о России. Эти понятия также не вошли в зону ядра, а попали в первую, в зону потенциальных изменений.

Кроме того, в число элементов первой периферической системы, составляющих потенциальную зону изменения, по убыванию частоты упоминания ассоциаций попали также следующие понятия: моя/наша, место, родная, семья, жизнь, будущее, страх, коррупция, история, застой, дно. В «периферическую зону», отражающую не единство группы, а, напротив, ее гетерогенность, многообразие идей и представлений ее членов, вошли также и ассоциации с чувственными категориями. В данном блоке эмоциональный тон снижен - появляются тревоги, разочарования, страх, гнев, бессилие, равнодушие, безысходность. Потенциальная зона изменений в так называемом в буферном поле периферийной зоны представлена радикально негативными элементами. Однако эта зона изменчива, противоречива, чувствительна к актуальному контексту ее существования, выполняя тем самым функции адаптации к реальностям сегодняшней жизни и защиты «ядра».

Расширение же зоны идентичности до глобальной возможно, но сопряжено с проблемой баланса глобальной и национально-государственной идентичностей. Исследование проблемы сохранения национально-государственной самобытности, культурного кода страны [31] в условиях расширения зоны идентичности до глобальной имело бы более конструктивное решение при обращении к основным методологическим подходам исследования личности в пространстве идентификационных процессов - символическому интеракционизму, когнитивному и конструктивистскому подходам.

Решение проблемы кризисного состояния идентичности, обострившегося в связи с цифровизацией всех сфер жизни в период пандемии, видится в поиске ответов на вопросы о существовании «цифровой культуры» [32], о базовых отличиях последней от традиционной культуры, о возможности, механизмах и последствиях изменений в сознании «цифрового человека» и общества в целом. 
Думается, что ответ - в психологии человека, в восприятии и переработке новой цифровой информации, в трансформации ценностно-символического пространства личности и общества. Понимая под трансформацией изменения в структуре индивидуального семантического пространства [33], можно утверждать, что механизм трансформации скрыт в конструировании и реконструировании социальных представлений. Современные информационно-коммуникационные технологии меняют структурно-функциональные и содержательно-морфологические характеристики социальных представлений о мире политики [34, с. 164], конструируя определенную картину мира вообще и политическую картину мира в частности.

Поскольку политическая картина мира как «система образов и представлений о власти и политике, ее структуре, механизмах и конфигурации в окружающей действительности, отражающей политический мир» [35, с. 123] подвижна и чувствительна к внешним стимулам, то содержащиеся в этой системе образов социальные представления подвержены изменениям посредством профилирования их когнитивных особенностей цифровым форматом коммуникации. Это происходит через влияние цифровых стимулов на психосемантическое пространство пользователя, обусловливая возрастание упорядоченности субъективной реальности, тем самым опосредуя осознание внутреннего мира человека и изменяя его.

Трансформация, имеющая два вида (сцепление и дифференциация), обусловлена личностными особенностями субъекта. То есть оба вида трансформации проходят через призму личностных факторов: индивидуальный опыт; ценностномотивационные предпочтения; осознаваемый и неосознаваемый Я-образ. Необходимо дополнительно изучить механизмы трансформации психосемантических пространств политической картины мира субъекта на уровне личности, в качестве которых выступают идентификация и проекция. К тому же цифровая среда неодномерна, не смешана, но и негомогенна, является не столько «пространством встречи смыслов и общения», как доказывалось в ранних исследованиях, сколько, согласно последним исследованиям, скорее пространством, включающим в себя две среды - «виртуальную» и «информационную» [36, с. 72-73]. Понимание того, что эти две среды имеют свои уникальные категории пользователей с разными целями, разными запросами на смыслы, с определенной направленностью сетевой активности, предполагает и прогнозируемую сложность пересечения и взаимодействия этих двух сред, с одной стороны, а также оформления и закрепления в сознании на уровне социальных установок классического идеального цифрового общества [37] в конкретной стране с устойчивыми национально-государственными механизмами идентификации - с другой. В то же время автор концепции «идентичности большинства» Л. Оргад выражает сомнение в реальности цифрового гражданства без изучения множества неопределенностей - политических, технологических и психологических [38], без учета которых последствия цифровой трансформации остаются неясными. 


\section{Выводы}

Явления техногуманитарного дисбаланса, разрыва между технологическим оптимизмом и социальным пессимизмом, усиливающиеся в условиях цифровизации жизни и социальных ограничений, актуализировали проблему национальногосударственной идентификации граждан и социально-политических рисков, носящих отложенный характер. Процессы изменения социальных представлений отслеживаются в научных исследованиях и демонстрируют следующие наблюдаемые тенденции: постепенная поляризация общества по типу «свой»-«чужой», в рамках которой проявляется противопоставление понятий «страна» и «государство», «гражданское общество» и «государство»; расширение и поляризация содержания идентификационных образов в сознании молодежи: «Россия-страна» и «Россия-государство», в том числе с позитивной и негативной коннотациями одновременно; исчезновение из ядра социального представления ассоциаций и образов, связанных с культурой; нарастающее ослабление чувства связанности и само-ассоциации граждан со своей страной; фрагментация идентичности по модели «все против всех» и замкнутость структур гражданского общества в рамках отдельных ниш.

Нарастающая поляризация молодежной аудитории в восприятии своей страны, противопоставление ассоциативных образов страны и государства могут переключить внимание молодых людей на других акторов политики, предлагающих иные символы и привлекательные образы в своих интересах. Социально-политическая стабильность тесно связана с проблемой национальногосударственной идентичности, среди факторов сохранения которой лежат не только составляющие политической картины мира, но и прежде всего историко-культурный контекст, позволяющий найти обществу ответ на экзистенциальный вопрос о смысле существования.

\section{Ссылки / References}

1. Абульханова К. А. Социальное мышление личности // Современная психология: состояние и перспективы исследований. Часть 3. Социальные представления и мышление личности. М.: Институт психологии РАН, 2002. С. 88-103.

2. Назаретян А. П. Цивилизационные кризисы в контексте Универсальной истории. М.: Пер Сэ, 2001. 340 c.

3. Нестик Т. А., Журавлев А. Л. Психология глобальных рисков. М.: Институт психологии PAH, 2018. 402 c.

4. Ж Журавлев А. Л., Нестик Т. А. Социально-психологические последствия внедрения новых технологий: перспективные направления исследований // Психологический журнал. 2019. Т. 40. № 5. С. 35-47.

5. Князева Е. Н., Курдюмов С. П. Основания синергетики. Режимы с обострением, самоорганизация, темпомиры. СПб.: Алетейя, 2002. 414 с.

6. Малинецкий Г. Г. Перспективы и технологии управления стратегическими рисками в первой половине XXI века // Стратегия гражданской защиты: проблемы и исследования. 2013. № 2. С. 15-17. 
7. Евгеньева Т. В., Титов В. В. Формирование национально-государственной идентичности российской молодежи // Полис. 2010. №4. С. 122-134.

8. Евгеньева Т. В. Идентификационное измерение образа страны: методы исследования и интерпретация результатов // Материалы IX международной социологической Грушинской конференции «Социальная инженерия: как социология меняет мир», 20-21 марта 2019 г. / Отв. ред. А. В. Кулешова. М.: АО «ВЦИОМ», 2019. С. 188-193.

9. З Зазнаев О. И. Национально-государственная идентичность: зарубежный опыт и Россия // Политическая идентичность и политика идентичности: очерки / Под ред. 0. И. Зазнаева; Казанский (Приволжский) федеральный университет. Казань: Отечество, 2011. С. 6-28.

10. Etoundi J. C., Kay N., Gaymard S. Social Representations of Risk in Cameroon: Influence of Sociopolitical and Cultural Context // Journal of Social and Political Psychology. 2020. Vol. 8 (2). P. 642-661. DOI: 10.5964/jspp.v8i2.1218.

11. Gaymard S. Pedestrian representation through the analysis of little stories // Psychology of Language and Communication. 2012. Vol. 16 (№ 3). P. 185-200. DOI: 10.2478/v10057012-0013-9

12. Gaymard S., Kay N., \& Etoundi J. C. Climate change and beliefs in Cameroon: A qualitative study among farmers in the Equatorial and Sudano-Sahelian zones // Canadian Social Science. 2015. Vol. 11 (№ 7). P. 53-64. DOI: 10.3968/7273

13. Joffe H. Risk: From perception to social representation // British Journal of Social Psychology. 2003. Vol. 42 (№ 1). P. 55-73. DOI: 10.1348/014466603763276126

14. Jaspal R., Nerlich B., \& Cinnirella M. Human responses to climate change: Social representation, identity and socio-psychological action // Environmental Communication. 2014. Vol. 8 (1). P. 110-130. DOI: 10.1080/17524032.2013.846270

15. Kmiec R., \& Roland-Lévy C. Risque et construction sociale: Une approche interculturelle [Risk and social construction: An intercultural approach] // Les Cahiers Internationaux de Psychologie Sociale. 2014/1. № 101. P. 69-99. DOI: 10.3917/cips.101.0069

16. Pigeaud F. Au Cameroun de Paul Biya [In Paul Biya's Cameroon]. Paris, France: Karthala, 2011. 276 c.

17. Ngahan T., \& Mukama N. Le Cameroun face au défi de la pauvreté et de l'emploi des jeunes: Analyse critique et propositions [Cameroon facing the challenge of poverty and youth employment: Critical analysis and proposals]. 2004 // Nations Unies. URL: http://www.un.org/esa/socdev/unyin/documents/wpaysubmissions/cameroun_jh.pdf (дата обращения: 29.01.2021).

18. Better governance improving education outcomes through better governance in Cameroon integrating supply and demand side approaches. 2012 // The World Bank IBRD IDA. April 11, 2012. URL: https://www.worldbank.org/en/news/feature/2012/04/11/bettergovernance-improving-education-outcomes-through-better-governance-in-cameroonintegrating-supply-and-demand-side-approaches (дата обращения: 29.01.2021).

19. Cameroun: La menace du radicalisme religieux [Cameroon: The threat of religious radicalism]. 2015 // International Crisis Group. URL: https://www.crisisgroup.org/fr/africa/central-africa/cameroon/cameroon-threatreligious-radicalism (дата обращения: 29.01.2021). 
20. Mvessomba E.-A., Deconchy J. P. Perception du réglage de l'appartenance entre groupes religieux (Catholiques traditionnels, Catholiques charismatiques et Chrétiens pentecôtistes au Cameroun) // Les Cahiers Internationaux de Psychologie Sociale. 2012/2 (№ 94). P. 319-341. // CAIRN.INFO. Matieres A Reflexion. URL: https://www.cairn.info/revue-lescahiers-internationaux-de-psychologie-sociale-2012-2-page-319.htm (дата обращения: 29.01.2021).

21. Дробижева Л. М. Российская идентичность в массовом сознании // Вестник Российской нации. 2009. № 1 (3). С. 135-144.

22. Дробижева Л. М. Российская идентичность: факторы интеграции и проблемы развития // Социологическая наука и социальная практика. 2013. № 1 (01). С. 74-84.

23. Дробижева Л. М. Российская идентичность: поиски определения и динамика распространения // Социологические исследования. 2020. № 8. С. 37-50.

24. Евгеньева Т. В. Историческая память и национально-государственная идентичность в современной России // Ценности и смыслы. 2012. № 5 (21). С. 27-36.

25. Moscovici S. La psychanalyse, son image et son public: Etude sur la représentation sociale de la psychanalyse [Psychoanalysis, its image and audience: Study of the social representation of psychoanalysis]. Paris, France, 1961. 650 c.

26. Abric J.-C. La recherche du noyau central et de la zone muette des représentations sociales [The search for the central core and the silent zone of social representations] // Méthodes d'étude des representations sociales [Methods of studying social representations] / J.C. Abric (Ed.), Ramonville-Saint-Agne. France: ÉRES, 2005. 2nd ed. P. 59-80 // CAIRN.INFO. Matieres A Reflexion.URL: https://www.cairn.info/methodes-d-etude-des-representationssociales--9782749201238.htm (дата обращения: 29.01.2021).

27. Verges P. Noyau central, sailanceet proprieties structurales // Textessur les representations sociales. 1994. № 3 (1). P. 3-12.

28. Flament C. Structure, dynamique et transformation des représentations sociales [Structure, dynamics and transformation of social representations] // Pratiques sociales et représentations [Social practices and representations] / In J. C. Abric (Ed.). Paris, France: PUF, 1994. P. 37-57.

29. Moliner P. La représentation sociale comme grille de lecture. Étude expérimentale de sa structure et aperçu sur ses processus de transformation [Social representation as a reading grid: Experimental study of its structure and overview of its transformation processes] (Unpublished doctoral dissertation). Aix-Marseille University, Marseille, France. 1988.

30. Gaymard S., Bordarie J. The perception of the ideal neighborhood: A preamble to implementation of a «street use code» // Social Indicators Research. 2015. Vol. 120 (3). P. 801-816. DOI: 10.1007/s11205-014-0610-1

31. Грищенко Ж. М., Сиверцев Ю. Г. Проблема культурного кода в социологическом измерении // Наука. Культура. Общество. 2020. № 2. С. 45-52.

32. Левашов В. К., Гребняк О. В. Цифровая культура российского общества и государства // Социологические исследования. 2020. № 5. С. 79-89.

33. Шмелев А. Г. Введение в экспериментальную психосемантику: теоретикометодологические основания и психодиагностические возможности. М.: Изд-во Моск. ун-та, 1983. 158 с. 
34. Щербина А. В. Императив цифровизации в социальных представлениях. Культурноисторическая перспектива // Возможности и угрозы цифрового общества: сборник научных статей / под общ. ред. А. В. Соколова, А. А. Власовой. Ярославль, 2019. C. $162-166$.

35. Самаркина И. В. Политическая картина мира: опыт концептуализации и интерпретации // Вестник Томского государственного университета. Философия. Социология. Политология. 2013. № 3 (23). С. 123.

36. Романов И. В. Психологические особенности влияния интернет-среды на личность. СПб.: Изд-во НУ «Центр стратегических исследований», 2016. 115 с.

37. Mossberger K., Wu Y., Crawford J. Connecting Citizens and Local Governments? Social Media and Interactivity in Major U.S. Cities // Government Information Quarterly. 2013. Vol. 30. № 4. P. 351-358.

38. Orgad L. The Future of Citizenship: Global and Digital - A Rejoinder // Debating Transformations of National Citizenship (ed. by R. Bauböck). IMIS COE Research Series. Springer, Cham. 2018. P. 353-358. DOI: 10.1007/978-3-319-92719-0_61 